\title{
EDIÇÕES FAC-SIMILAR E SEMIDIPLOMÁTICA DE UM AUTO DE DEFLORAMENTO DE 1914
}

\author{
Jéssica Pâmela Bomfim Silva $^{1}$; Josenilce Rodrigues de Oliveira Barreto ${ }^{2}$ \\ 1. Bolsista PEVIC, Graduanda em Letras Vernáculas, Universidade Estadual de Feira de Santana, e-mail: \\ jelbomfim@live.com \\ 2. Orientadora, Departamento de Letras e Artes, Universidade Estadual de Feira de Santana, e-mail: \\ nilce11.barreto@gmail.com
}

PALAVRAS-CHAVE: Filologia; Edições fac-similar e semidiplomática; Codicologia.

\section{INTRODUÇÃO}

A Filologia é uma ciência antiga que tem por objeto de estudo o texto. Segundo Cambraia (2005, p.18), a Filologia possibilita "[...] o estudo global de um texto, ou seja, a exploração exaustiva e conjunta dos mais variados aspectos de um texto: lingüístico, literário, crítico-textual, sócio-histórico, etc." Dessa maneira, a ciência filológica permite aos filólogos estudarem, interpretarem e comentarem os documentos, por diversos vieses.

De acordo com Melo (1971), existem quatro tipos de edições, a saber: a princeps (primeira edição de uma obra antiga); a crítica (que permite a comparação de manuscritos para estabelecer o texto perfeito); a diplomática (que preserva o texto ipsis litteris); e a facsimilar (feita através da fotografia, da digitalização etc.).

Outra edição existente não mencionada por Melo (1971) é a semidiplomática, que propicia a conservação das informações presentes no texto de forma fidedigna, porém a mesma permite algumas interferências no sentido de desdobrar as abreviaturas, apresentandoas em itálico e, também, separar as palavras unidas e unir as palavras separadas, o que facilita a leitura do documento por parte de interessados em geral. Assim, para esta pesquisa, propomos as edições fac-similar e semidiplomática do Auto de Defloramento de 1914, de Lindaura Maria de Jesus, para tornar possível a perpetuação das informações constantes no manuscrito, através das edições supracitadas.

\section{MATERIAIS E MÉTODOS}

O material utilizado para o desenvolvimento de tal pesquisa foi o Auto de Defloramento de Lindaura Maria de Jesus, datado de 1914. Além disso, foi necessária a utilização de luvas para evitar o desgaste físico do documento, cuja fragilidade é perceptível devido, sobretudo, às ações do tempo.

Em relação aos métodos foram seguidas três etapas:

1- Registro fac-similar do corpus;

2- Edição semidiplomática do documento, para a qual foram observados os seguintes critérios, baseados em Queiroz (2007, p. 34):

Para a descrição, observamos:

Número de colunas;

Existência de ornamentos; 
Maiúsculas mais interessantes;

Existências de sinais especiais e abreviaturas;

Tipo de escrita e tipo de papel.

Para a transcrição, optamos por:

Respeitar fielmente o texto: grafia, linhas, fólios, cor da tinta utilizada etc.;

Fazer remissão ao número do fólio no ângulo superior direito;

Numerar o texto linha por linha, constando a numeração de cinco em cinco;

Separar as palavras unidas e unir as separadas;

Desdobrar as abreviaturas usando itálico;

Utilizar colchetes para as interpolações;

[ ] Indicar as rasuras, acréscimos e supressões através dos seguintes operadores:

$((\dagger))$ rasura ilegível;

$[\dagger]$ escrito não identificado;

(...) leitura impossível por dano do suporte;

/ / leitura conjecturada;

<> supressão;

( ) rasura ou mancha;

[ ] acréscimo;

$[\uparrow]$ acréscimo na entrelinha superior;

As partes impressas estarão em negrito.

3- Levantamento das características paleográficas e filológicas do corpus.

\section{ANÁLISE E DISCUSSÃO DOS RESULTADOS}

A descrição de um documento diz respeito aos detalhes contidos no mesmo. Assim, no Auto de Defloramento foram observados alguns pormenores, tais quais: o manuscrito é da esfera crime, lavrado entre os anos de 1914 a 1924, contém 89 fólios (escritos no recto e verso), está localizado em um arquivo público denominado Centro de Documentação e Pesquisa (CEDOC), órgão da Universidade Estadual de Feira de Santana (UEFS). O processo estudado encontra-se na caixa 110, estante 4 e documento de número 2279 , o qual foi escrito em papel almaço, em letra cursiva, em tinta preta e apresenta algumas partes escritas na cor verde.

O manuscrito retrata a história de Lindaura Maria de Jesus, que foi desvirginada pelo seu noivo João de Vasconcellos. Como a vítima foi desonrada, o réu deveria contrair matrimônio para reparar-lhe a honra, porém não foi o que ele fez, pois o mesmo recusou-se casar com a ofendida e assumir a criança (mais tarde registrada como Antonia), visto que a jovem ficou grávida após o seu defloramento. Dessa forma, o Processo Crime de Defloramento foi instaurado e, depois de 10 anos, João de Vasconcellos foi condenado a quatro anos de prisão, mas o crime prescreveu e ele só pagou as custas do processo. Vale salientar que Lindaura Maria de Jesus nasceu em 31 de janeiro de mil oitocentos e noventa e cinco, era filha de Idalina Maria de Jesus e de Avelino José da Costa, não sabia ler e nem escrever, residia no distrito de Almas (atual município denominado de Anguera-Bahia) e, segundo testemunhas, era "alva", honesta, trabalhadora, de "bons costumes" e só saía na companhia de seus pais.

A seguir, seguem alguns exemplos das edições fac-similar e semidiplomática do Auto de Defloramento de Lindaura Maria de Jesus, de 1914: 
Figuras 1 e 2: Edições fac-similar e semidiplomática dos fólios 16r e 16v, nos quais é descrito o depoimento de Lindaura Maria de Jesus.

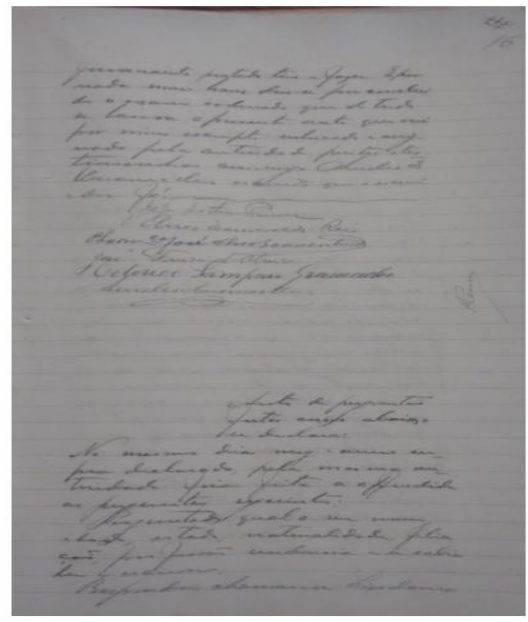

$$
\begin{aligned}
& \begin{array}{l}
\text { juramento prestado têm a fazer. E por } \\
\text { nada mais a haver deu-se por conclui- }
\end{array} \\
& \text { do o exame ordenado que de tudo } \\
& \text { se lavrou o presente auto que vai } \\
& \text { por mim escripto rubricado e assig- } \\
& \text { timunhas comigo Aurelio de } \\
& \text { Vasconcellos escrivão que o escrevi } \\
& 10 \text { e dou fé. } \\
& \text { sep [Assinatura] } \\
& \text { [Assinatura] } \\
& \text { [Assinatura] } \\
& \text { [Assinatura] } \\
& 15 \text { [Assinatura] }
\end{aligned}
$$

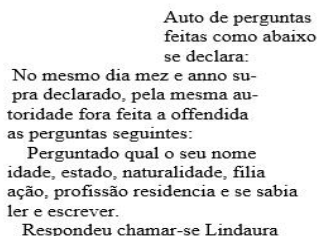

f. $16 \mathrm{r}$

Figura 3: Alguns aspectos codicológicos do processo de defloramento de Lindaura Maria de Jesus.

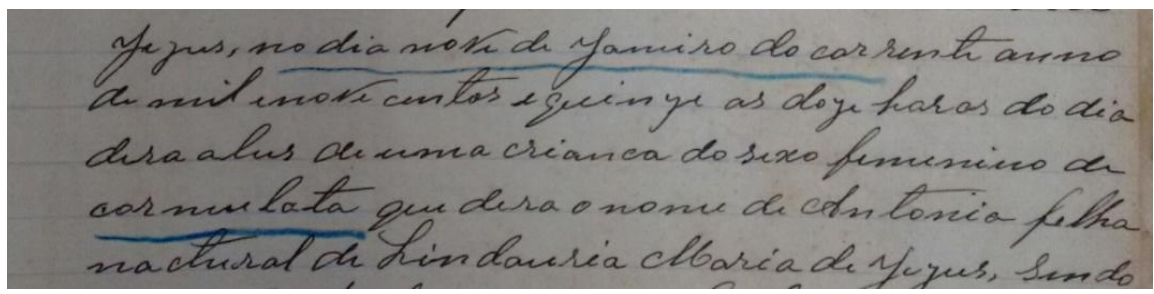

Giz de

cera na cor azul- f.65r

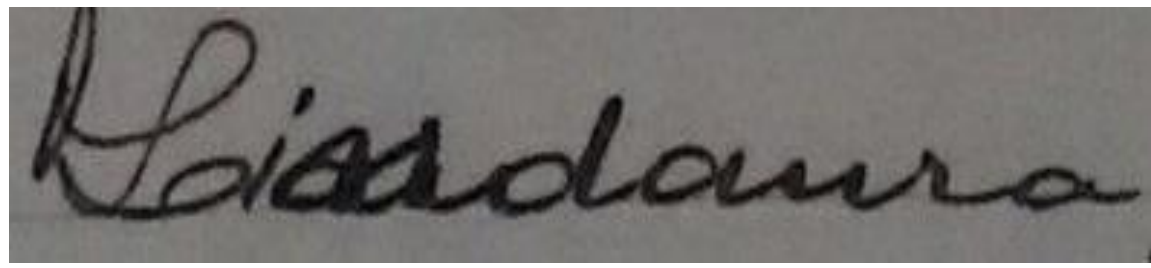

Rasura - f. 64r

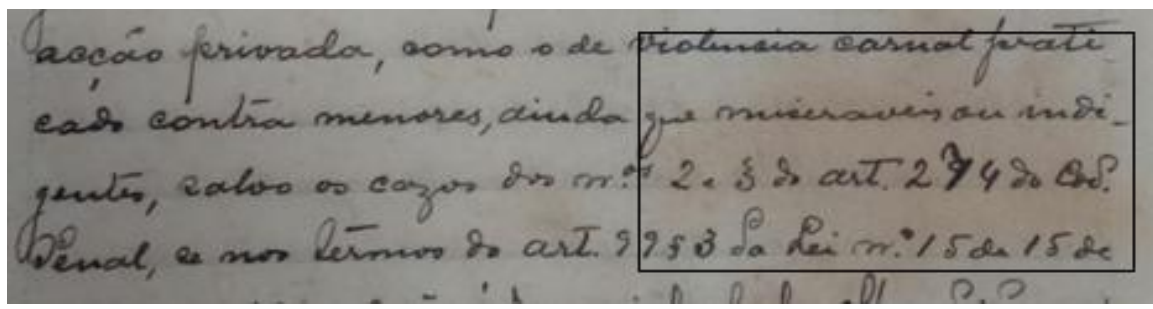

Mancha - f. 59v 


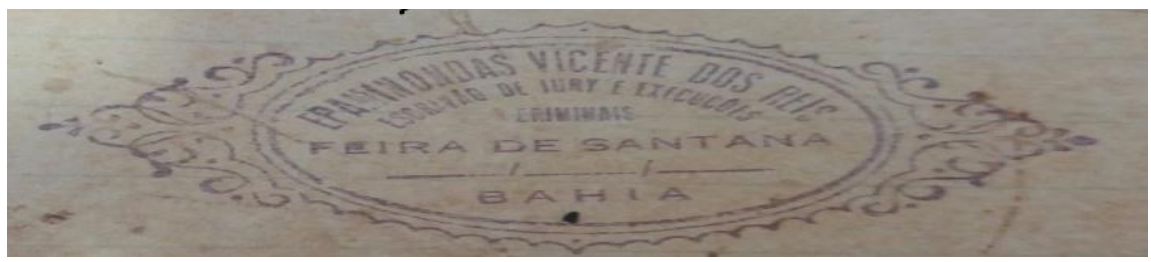

Carimbo do escrivão Epaminondas Vicente dos Reis - f.1r

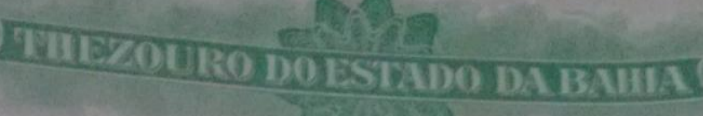

Inscrição "Thesouro do Estado da Bahia” presente em quase todos os fólios recto f.26r

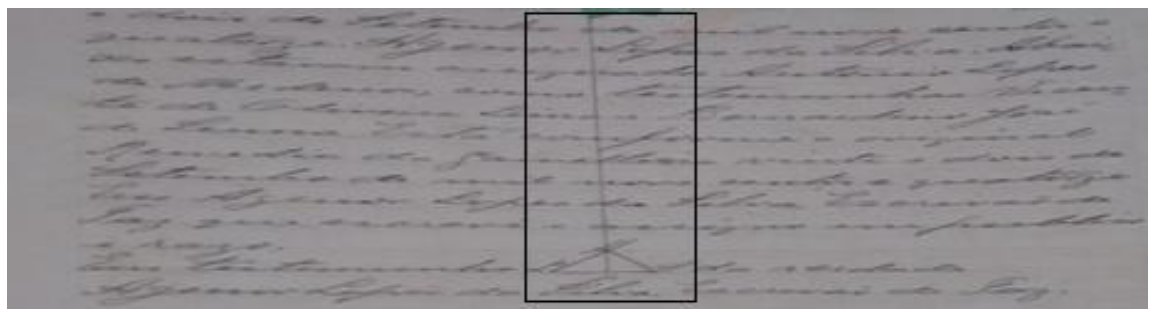

Sinal especial feito pelo escrivão Agenor Lopes da Silva - f.28r

\section{CONSIDERAÇÕES FINAIS}

Vários estudiosos de diversas áreas, principalmente os filólogos, concordam que os documentos são corpora essenciais que revelam fatos históricos e culturais de um povo. Entretanto, ainda nos cabe questionar sobre o que seria do presente e do futuro sem o passado documental? Através dos documentos, podemos ter acesso a um pretérito que revela a história da humanidade, pois "É preciso caminhar em direção ao futuro, com um olho fixo no horizonte e outro atento ao retrovisor do passado." (SILVA, 1994, p.13). Logo, é indispensável olhar para o passado através dos manuscritos e ter acesso às informações contidas no mesmo.

Portanto, ao termos acesso ao Auto de Defloramento supracitado, através das edições filológicas, temos contato com um universo riquíssimo, pois podemos conhecer a história de Lindaura Maria de Jesus que nos apresenta como a sociedade tratava uma mulher desvirginada e mãe solteira, além de termos acesso à língua, às leis sociais, aos saberes, à moral, aos hábitos, às crenças da sociedade local de 1914.

\section{REFERÊNCIAS}

CAMBRAIA, César Nardelli. Introdução à crítica textual. São Paulo: Martins Fontes, 2005.

MELO, Gladstone Chaves de. Iniciação à Filologia e à Linguística Portuguesa. 5. ed. Rio de Janeiro: Acadêmica, 1971.

QUEIROZ, Rita de Cássia Ribeiro de. Introdução metodológica. In: . (Org.). Documentos do acervo de Monsenhor Galvão: edição semidiplomática. Feira de Santana: Universidade Estadual de Feira de Santana, 2007. p. 23-34.

SILVA, Leonardo Dantas. Apresentação. In: ACIOLI, Vera Lúcia Costa. Escrita no Brasil colônia: um guia para a leitura de documentos manuscritos. Recife: Massangana, 1994. p. 13- 14. 